\title{
Olive Ridley Nest Destiny on Pelada Beach, Costa Rica
}

Autumn Zwiernik* and Vanessa Bézy, PhD†

*To whom correspondence should be addressed: zwiernik@umich.edu †TORTUGuiones@gmail.com

The olive ridley sea turtle population is in decline due to factors including egg take and nest destruction. This study describes the investigation of the destiny of olive ridley turtle nests on Pelada beach in Nosara, Costa Rica. Nest destinies were categorically classified as one of the following: poached, depredated, or incubated, categorized using non-invasive visual beach surveys conducted between December 2015 and November 2018 in a combined effort headed by a local environmental nonprofit TortuGuiones. The effort was designed to quantify the human-caused destruction of olive ridley sea turtle nests relative to other outcomes on Pelada beach. Fifty-two nests were classified and recorded by ten volunteer surveyors. The results indicated that $49 \%$ $( \pm 15 \%)$ of nests were poached and $9 \%( \pm 8 \%)$ of nests were depredated, likely by domesticated dogs. This supports the hypothesis that humans have a significant site-specific impact on olive ridley nest success, both directly through the harvest of eggs and indirectly through their domesticated dogs. These observations suggest that further studies designed to assess the impact of this frequency of human-caused nest destruction on reproduction and population survival are warranted as a basis to establish the best available practices for local population sustainability.

\section{Introduction}

The olive ridley sea turtle, which is found in tropical and warm-temperate ocean habitats, is considered the most abundant sea turtle in the world. ${ }^{1}$ However, its population is in decline primarily due to human activities which include: harvest of adults and eggs, bycatch by fisheries, and destruction of nesting habitats. ${ }^{2}$ Currently, the breeding populations on the Pacific Coast of Mexico are endangered and all other populations are listed as threatened under the Endangered Species Act. ${ }^{3}$ Reproductive behavior is variable between olive ridley populations, and whether this affects nest success and population sustainability is not well understood.

The olive ridley sea turtle is unique for its mass nesting behavior called arribada, during which females gather, come ashore, and nest all at once on a small stretch of beach. ${ }^{4}$ Only one other species of sea turtle, the kemp's ridley, have arribadas. ${ }^{3}$ This synchronized nesting behavior makes the olive ridley highly vulnerable to the harvesting of eggs and adults, as arribadas are predictable and the density of nesting females makes locating both adults and eggs possible with minimal effort. According to the World Wildlife Fund, the main active arribada nesting beaches exist on the pacific coast of Central America and in India. ${ }^{1}$ They account for the majority of olive ridley nests, but not all females nest in arribadas. Some nest in small aggregations and others nest solitarily, often on beaches near arribadas such as Pelada beach in the Northwestern Pacific region of Costa Rica. The National Oceanic and Atmospheric Association has noted that the importance of solitary nesters may be underestimated by the scientific community because nests in these areas may have a lower depredation and poaching rate than arribada beaches, however, this has not been substantiated partially because studies of solitary nesting beaches are not often carried out. ${ }^{5}$

Olive ridley sea turtles are integral to the marine and coastal ecosystems that they inhabit, and they are beneficial to the community. In the marine ecosystem, olive ridley sea turtles help maintain the health of coral reefs and seagrass beds. ${ }^{1}$ Olive ridley sea turtles are also important to coastal ecosystems where they transfer highly concentrated nutrients into coastal environments through their unhatched eggs 
and eggshells which help support the growth of vegetation and maintain stable dune systems. ${ }^{6}$ In addition to their environmental functions, olive ridley sea turtles stimulate economic income for local communities such as the community surrounding the Ostional National Wildlife Refuge by supporting significant ecotourism. ${ }^{7}$ People from around the world travel to the Ostional National Wildlife Refuge each year, where they buy food at local restaurants and pay native Ostional residents for tours of the refuge. For these reasons, as well as aesthetic and ethical considerations, it is important to the environment and the community that olive ridley populations remain robust and sustainable.

Globally, olive ridley sea turtle populations are in decline and vulnerable to extinction. ${ }^{2}$ It is apparent that possible solutions abound, including the enforcement of existing laws, international pressure, education of the public, the use of turtle excluder devices in fishing nets, and more. In order to succeed in maintaining a sustainable olive ridley population or returning the species to previous levels, the conservation and management approach will have to be multifaceted and ambitious, involving local communities, national governments, and international changes.

The purpose of this study is to quantify the site-specific nest destinies of olive ridley sea turtles on Pelada beach and determine whether these nest destinies indicate a significant site-specific impact of human activity on nest incubation and ultimately nest outcomes.

\section{Methods}

\section{Study Site}

Pelada beach is an approximately one kilometer stretch of coast on the edge of the Ostional National Wildlife Refuge. Since Pelada beach is within the Ostional National Wildlife Refuge, habitat modification and development are prohibited within two hundred meters of the high tide line according to the Costa Rican National System of Conservation Areas and Ministry of the Environment and Energy. Although there is public access, the harassment of turtle nests and/or harvest of eggs on Pelada beach is always illegal. Despite this, anecdotal evidence suggests that olive ridley turtle nests on Pelada beach experience a high mortality rate because of factors including depredation by feral dogs and illegal egg taking for sale and human consumption. To date, there have been no controlled studies quantifying this issue.

\section{Ostional National Wildlife Refuge}

The Ostional National Wildlife Refuge was established in $1984,{ }^{8}$ and it includes Pelada (described above), Guiones, Nosara, and Ostional beaches (Figure 1). Of these only Ostional beach is considered to be an arribada or mass nesting beach. Based on estimates over a study period of 2006-2010 a single arribada event at the Ostional beach can attract up to 476,550 egg-laying females. ${ }^{9}$ Given that the WWF estimates approximately 800,000 egg-laying females exist in the world today, it is expected that Ostional is one of the most important areas in the world for nesting of the olive ridley turtle.

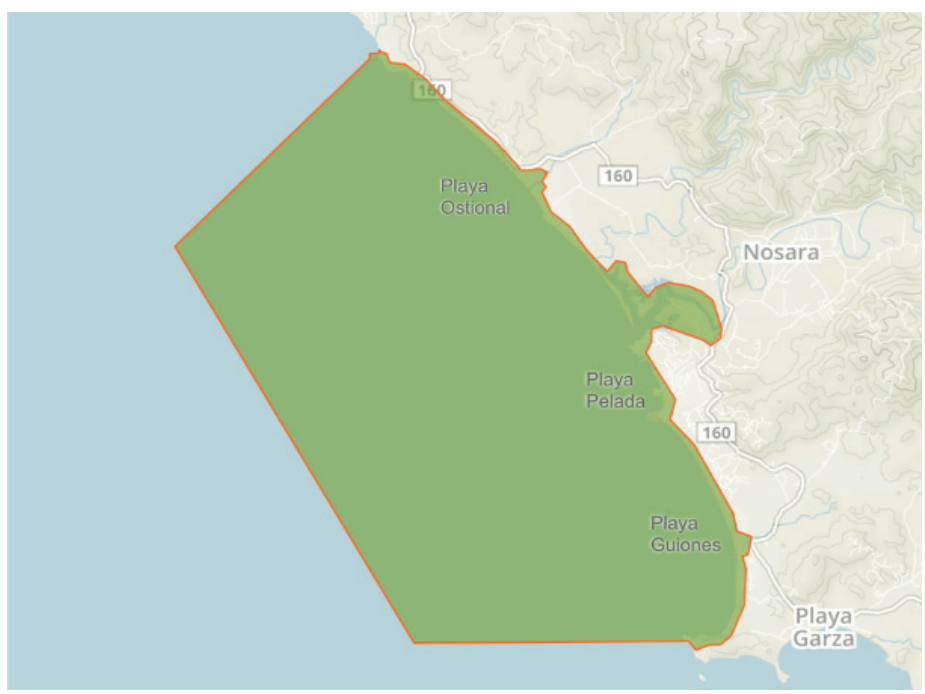

Figure 1. Map of Ostional National Wildlife Refuge. The refuge is highlighted in green and includes the beaches of Ostional, Pelada, and Guiones.

Fascinatingly, Ostional beach is not large enough to accommodate all of the turtles who nest there, so some of the first eggs to be laid are crushed by the digging activity of turtles who arrive later to nest. Aside from being one of the most important sites for olive ridley nesting, Ostional is also the only beach in the world that has instituted a program for legal harvesting of eggs. ${ }^{10}$ The Ostional Development Association and biologists from the Tempisque Conservation Area oversee the removal of eggs by Ostional locals during the first 48 hours of nesting that may have otherwise been destroyed. After the 48-hour period, human nest take is prohibited. However, mortality may remain high due to high nest destiny, microbes, and high nest temperatures. ${ }^{9}$ This legal egg take program does not extend to Pelada beach, where nest density is much lower. 


\section{Visual Surveys}

Data was collected by citizen scientists using visual beach surveys of Pelada beach between 2015 and 2018. Over the course of the study, there was minimum interference with the natural environment, and no manipulation of turtles or eggs. All volunteers were trained using a standard presentation with diagrams to identify sea turtle species and their tracks. They were asked to walk the beach in the morning and report any activity via an electronic form (Appendix A). TortuGuiones asks volunteers to report all sightings of sea turtle nests, hatchlings, and adults. However, reports of live or dead sea turtles were set aside, as they do not help to answer the question of nest destinies.

According to local biologist and the President of TortuGuiones, Vanessa Bézy, sea turtle eggs on Pelada beach are generally either poached the night they are laid or left undisturbed to hatch. This is likely due to two things: (1) the majority of poaching occurs at night when the beach is not populated, and (2) people who harvest eggs illegally rely on the sea turtles' tracks in the sand to locate their buried nests, but these tracks are washed away by the tide within twelve hours of the eggs being laid. This leaves eggs most vulnerable the night they are laid. Visual beach surveys were conducted early in the morning in order to avoid confrontation while maximizing the chance of observing the sea turtle tracks before they are washed away.

Once located using tracks (Figure 2), each nest was then classified as undisturbed, poached, or predated based on the presence of the following predefined characteristics which were established by TortuGuiones founder and Nosara resident marine biologist Vanessa Bézy and employed by all citizen scientists who contributed to data collection as well as the author:

- Incubating - nest in natural, unaltered condition, no exposed eggs or holes

- Poached - footprints, poke marks, a stick, and/or motorized vehicle tracks

- Depredated - paw prints, claw marks, exposed eggs, broken eggshells, dogs encountered eating eggs and/or hatchlings

Photographic records of tracks and nests were taken whenever possible by all surveyors but were not required in volunteers' reports. Tracks from false crawls, which occur when a sea turtle crawls onto the beach but goes back to the water without digging a nest or laying eggs, were not recorded.
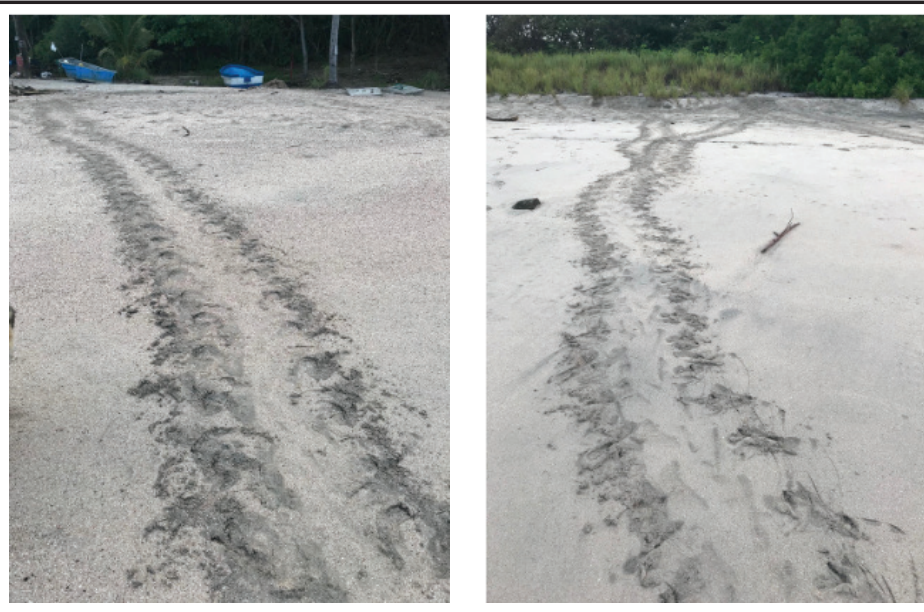

Figure 2. Examples of olive ridley tracks photographed on Pelada beach by the author on November 2, 2018.

\section{Results}

Fifty-two olive ridley nests were identified on Pelada beach and classified as poached, depredated, incubating, or "not sure" during a study period of approximately three years. Twenty-two nests were classified as poached and four were classified as depredated (Appendix B - Table 1). Nineteen were classified as undisturbed. Seven nests were reported as "not sure." For the purpose of data analysis, only the fortyfive nests which were classified as either poached, depredated, or incubating were considered.

Figure 3 below shows the percent distribution of nest fates by observed category including "not sure" which was recorded when the observer could not confidently identify

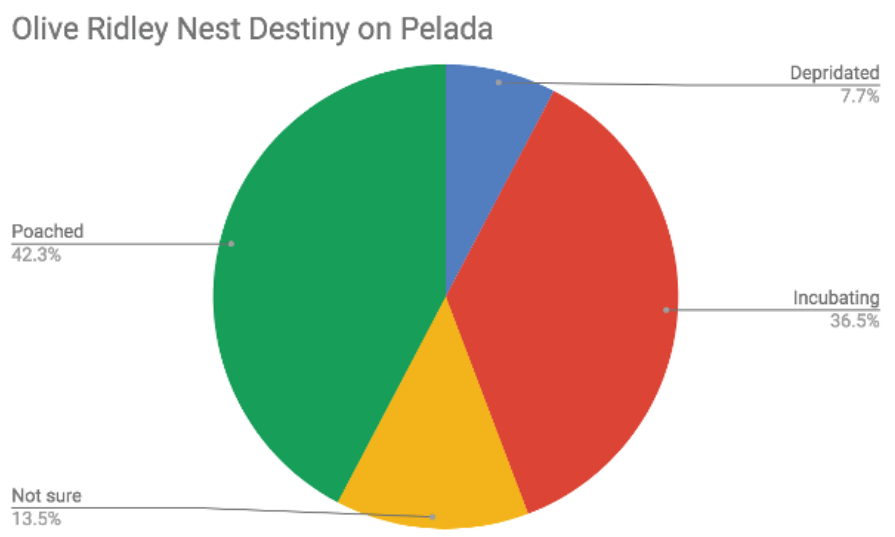

Figure 3. Destiny Frequency (\%) of Olive Ridley (Lepidochelys olivacea) Nests on Pelada beach, Guanacaste, Costa Rica, according to visual surveys between December 2015 and November 2018. $\mathrm{n}=52$. Nests classified as "Not Sure" are included in this figure. 
the condition. Based on survey results where the observer confidently identified the nest fate, $42 \%$ of nests were undisturbed, $49 \%$ were poached, and another $9 \%$ were depredated. It can be said with $95 \%$ confidence that 35 to $80 \%$ of nests on Pelada beach are either poached or depredated (Appendix $\mathrm{B}$ - Table 2). Although the conclusion is not precise it demonstrates that a sufficient percentage of nests are being interrupted to justify taking measures to prevent poaching and depredation by domesticated animals.

Although there has been no previous study of sea turtle nesting on Pelada beach, it has been established that peak olive ridley nesting on frequently studied Ostional beach generally occurs during the rainy season, which is between the months of May and November, with less nesting activity in the dry season. ${ }^{11}$ As seen in Figure 4, the frequency of nests identified by month for this study seems to mirror that cycle in December 2015 through fall 2017, but near December 2017 we do not see the spike of nests identified that we would expect to correlate with increased nesting activity that time of year. This break from the expected pattern is of unknown cause, but one explanation could be that the level of survey effort was not consistent over the study period.

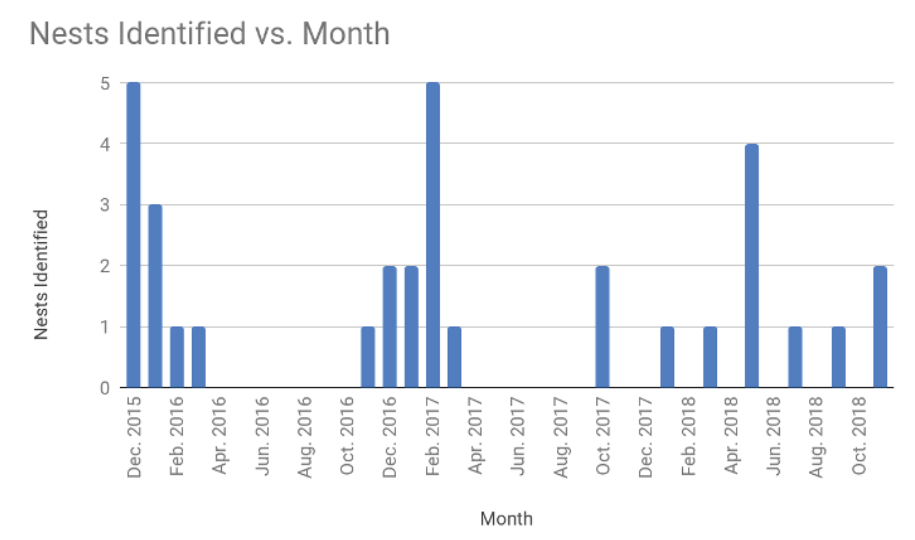

Figure 4. Olive Ridley (Lepidochelys olivacea) Nests Identified by month during visual surveys of Pelada beach in the Ostional National Wildlife Refuge, Guanacaste, Costa Rica, between December 2015 and November 2018. $\mathrm{n}=52$.

During the study period, a nest was identified at least once during every month of the year except June and August. This indicates that Pelada beach is a valuable nesting habitat for olive ridley sea turtles year-round. Understanding the timing of turtle arrivals is important for creating an effective protection plan.

\section{Discussion}

This project included the involvement and education of the local community through TortuGuiones conservation initiatives as well as community activities, such as the creation of aerial environmental art on Pelada beach (Figure 5). Through this involvement, local citizen scientists contributed an estimated 100 person-hours. The observations made by these volunteers demonstrate that there is a significant population of olive ridley sea turtles nesting on Pelada beach and reaffirms the importance of Pelada beach's protected status. The conclusions drawn may be used to pursue funding for more a definitive study of population level effects of anthropological nest disturbance in order to further investigate the impact of this high mortality of solitary nesting olive ridley turtles' eggs on the olive ridley population.

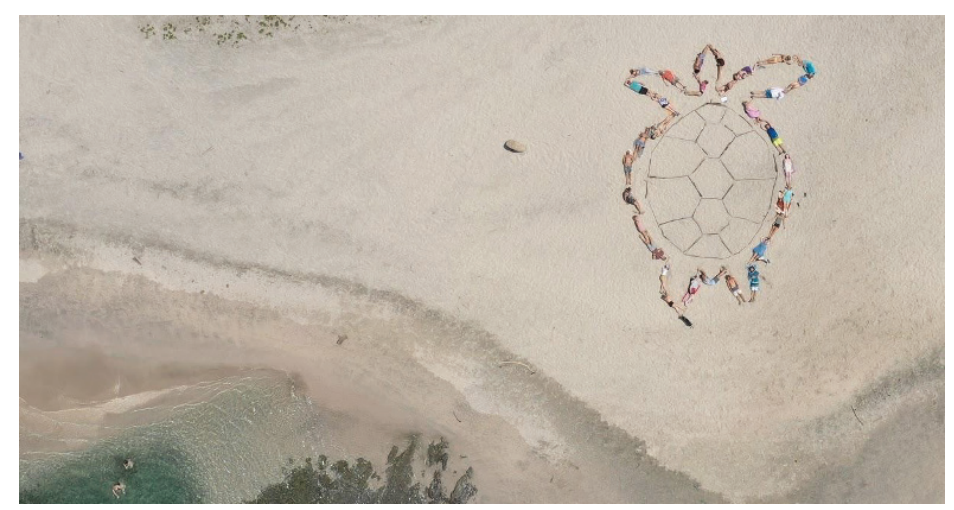

Figure 5. An aerial photograph of local community members laying on Pelada beach in the shape of a sea turtle. Community activity organized and executed by the student author on February 17, 2019.

The data gathered indicates that the nesting population on Pelada beach experiences a poaching rate of $49 \%( \pm 15 \%)$. This is a poaching rate greater than any other published values including a $45 \%( \pm 4.4 \%)$ poaching rate recorded during a "mass invasion by poachers" on La Flor beach, an arribada beach in Nicaragua. ${ }^{4}$

Although we cannot be sure what percentage of nests classified as depredated were depredated by dogs, and not by a wild animal such as the white-nosed coatis (Figure 6) which reside in the area and are ground foraging omnivores, ${ }^{12}$ we can be relatively certain that some if not most of the depredation is done by dogs because of anecdotal evidence of dogs seen eating sea turtle eggs by the student and others, and because of paw prints found around nests which resemble those of domestic dogs.

According to an estimate in the eastern Pacific, nesting 


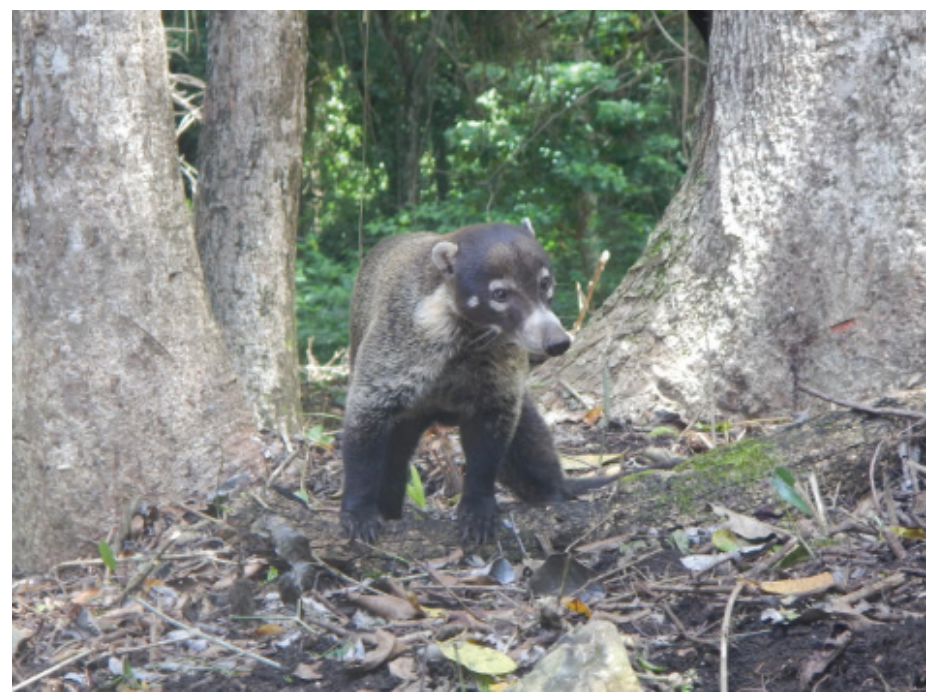

Figure 6. White-nosed coati seen foraging in the jungle $500 \mathrm{~m}$ from Pelada beach. Photographed by the student on November 15, 2018.

female olive ridleys were found to lay an average of 105 eggs. ${ }^{13}$ As this study has documented twenty-two poached nests, we can estimate that those nests represent 2,310 olive ridley sea turtle eggs illegally removed from Pelada beach. Since nests were identified during every month of the year except June and August, the olive ridley sea turtles are likely using Pelada beach as a nesting ground year-round. It is possible that seasonal peak nesting generally occurs around December and fewer nesting attempts occur in the months of June, July, and August, although this cannot be established concretely due to the varying level of survey effort. The pattern of use of Pelada beach as a nesting ground suggests that if anti-poaching or depredation measures are put in place on Pelada beach, they would be beneficial year-round; however, in instances where resources are limited, the greatest costbenefit may occur between November and February.

Female olive ridleys, like most sea turtle species, return to the same area where they were born to nest. Because olive ridley sea turtles take an estimated ten to fifteen years to reach sexual maturity, ${ }^{14}$ the results of decreased poaching and depredation would not be immediately observable. Solutions to the significant rate of nest destruction by poaching and depredation by domesticated dogs on Pelada beach should be implemented as soon as possible so that their results can be measurable by 2035 .

\section{Conclusion}

Based on the fifty-two nests classified on this non-arribada location, it can be concluded that not only is there a siz- able population of olive ridley sea turtles nesting on Pelada beach, but that nesting population is experiencing poaching at a rate higher than reported in studies of arribada beaches. This indicates that non-arribada beaches, which host solitary nesting olive ridley sea turtles and are rarely studied, may be subject in some cases to an even higher poaching rate than arribada beaches.

The site-specific nest destinies of olive ridley sea turtles on Pelada beach $(49 \%( \pm 15 \%)$ poached and $9 \%$ ( $\pm 8 \%)$ depredated by domesticated animals) do indicate a significant site-specific impact of human activity on nest incubation and ultimately nest outcomes. This suggests that further studies, designed to assess the impact of this frequency of humancaused nest destruction on reproduction and population survival, are warranted as a basis to establish the best available practices for local population sustainability. This author encourages the Nosara community to continue to research and advocate for the local nesting population of olive ridley sea turtles.

\section{Acknowledgements}

Thank you to Vanessa Bézy for teaching me about our local olive ridley population, and thank you to her volunteers who helped collect data by walking the beach at sunrise, scanning for sea turtle tracks. Without Vanessa's mentorship and our community's passion for wildlife, none of this would have been possible. All data was collected as a part of the TortuGuiones sea turtle conservation project under Costa Rican scientific research permits (ACT-OR-DR-108-15, ACT-ORDR-090-16, ACT-OR-DR-030-17, ACT-OR-DR-103-18).

\section{References}

WWF. "Olive Ridley Turtle." WWF, World Wildlife Fund, 2018, www.worldwildlife.org/species/olive-ridley-turtle.

Abreu-Grobois, A \& Plotkin, P. (IUCN SSC Marine Turtle Specialist Group) 2008. Lepidochelys olivacea. The IUCN Red List of Threatened Species 2008: e.T11534A3292503. http://dx.doi.org/10.2305/IUCN. UK.2008.RLTS.T11534A3292503.en.

NOAA “Olive Ridley Sea Turtle (Lepidochelys Olivacea) 5-Year Review: Summary and Evaluation.” NOAA, 4 June 2018, www.fisheries.noaa.gov/resource/document/ olive-ridley-sea-turtle-lepidochelys-olivacea-5-yearreview-summary-and.

Honarvar, Shaya, et al. "Microbial Community Structure in Sand on Two Olive Ridley Arribada Nesting 
Beaches, Playa La Flor, Nicaragua and Playa Nancite, Costa Rica." Journal of Experimental Marine Biology and Ecology, vol. 409, no. 1-2, 2011, doi:10.1016/j. jembe.2011.09.015.

NOAA. "Olive Ridley Turtle." NOAA Fisheries, www.fisheries.noaa.gov/species/olive-ridley-turtle.

Bouchard, Sarah S, and Karen A Bjorndal. Sea Turtles as Biological Transporters of Nutrients and Energy From Marine to Terrestrial Ecosystems. Ecological Society of America, 2000, onlinelibrary.wiley.com/doi/ abs/10.1890/0012-9658(2000)081[2305:STABTO]2.0 $\mathrm{CO}$;

Budiantoro, Agung, C Retnaningdyah, L Hakim, and A S Leksono. "The Sustainable Ecotourism Potential Development with Special Reference to Olive Ridley Sea Turtle (Lepidochelys olivacea) Along Bantul Beaches, Indonesia." Earth and Environmental Science, 391 (2019) 012069 doi:10.1088/1755-1315/391/1/012069

Ross Yazmín, et al. Costa Rica: Nature Unbound. Ojalá Ediciones, 2013.

Valverde, Roldán A., et al. "Olive Ridley Mass Nesting Ecology and Egg Harvest at Ostional Beach, Costa Rica." Chelonian Conservation and Biology, vol. 11, no. 1, 2012, pp. 1-11., doi:10.2744/ccb-0959.1.

Embassy of Costa Rica in Washington DC. "OSTIONAL WILDLIFE REFUGE TURTLE MONITORING AND HARVESTING." Environment | Embajada De Costa Rica En DC, www.costarica-embassy.org/index. php?q=node $/ 106$.

Bézy, Vanessa S., et al. "Estimation of the Net Nesting Effort of Olive Ridley Arribada Sea Turtles Based on Nest Densities at Ostional Beach, Costa Rica." Journal of Herpetology, vol. 50, no. 3, 2016, pp. 409-415., doi:10.1670/14-152.

“White-Nosed Coati." Smithsonian's National Zoo, 17 July 2018, nationalzoo.si.edu/animals/white-nosed-coati.

Jackson, Dale R., et al. "Turtles of the United States and Canada." Copeia, vol. 1995, no. 4, 1995, p. 998., doi:10.2307/1447059.

"Olive Ridley Sea Turtle." The National Wildlife Federation, www.nwf.org/Educational-Resources/Wildlife-Guide/ Reptiles/Sea-Turtles/Olive-Ridley-Sea-Turtle.

\section{Appendices}

Appendix A: Electronic form used by TortuGuiones to record volunteer reports

\section{Report Sea Turtle Activity}
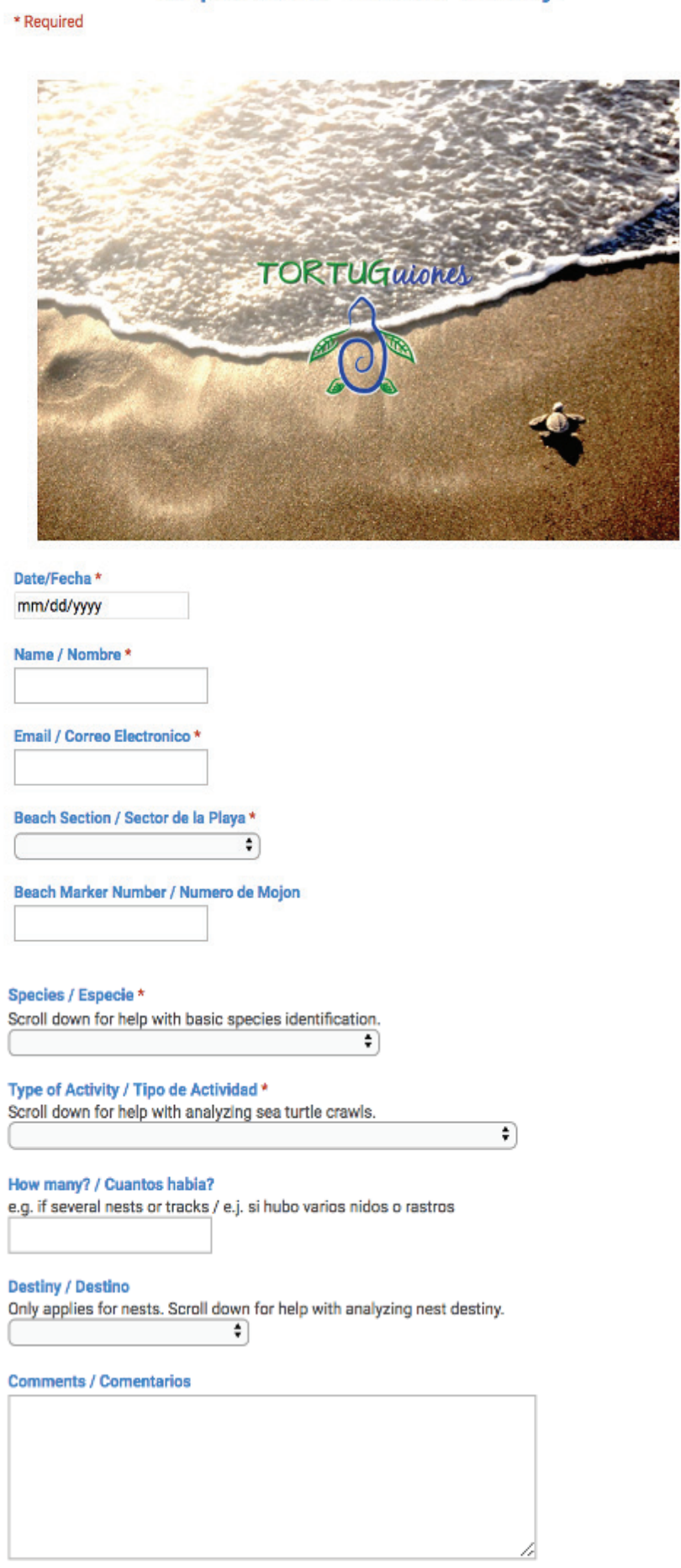

Thank you! Scroll down to submit.

If you have any photos, please email them to TORTUGuiones@gmail.com or post to social media using our hashtag \#TORTUGuiones. 
Appendix B: Tables

Table 1. Olive Ridley (Lepidochelys olivacea) Nests identified during visual surveys of Pelada beach in the Ostional National Wildlife Refuge, Guanacaste, Costa Rica, between December 2015 and November 2018, classified by nest destiny. $\mathrm{n}=52$.

\begin{tabular}{lc}
\hline Nest Destiny by Classification & \\
\hline Classification & Number of Nests \\
\hline Poached & 22 \\
Depredated & 4 \\
Incubating/Undisturbed & 19 \\
Not Sure & 7 \\
\hline
\end{tabular}

Table 2. Relative frequency of nest destiny classifications of O1ive Ridley (Lepidochelys olivacea) Nests identified during visual surveys of Pelada beach in the Ostional National Wildlife Refuge, Guanacaste, Costa Rica, between December 2015 and November 2018. Nests not classified are excluded.

\begin{tabular}{lcc}
\hline \multicolumn{3}{l}{ Relative Frequencies of Classifications } \\
\hline Classification & Relative Frequency & $95 \%$ Confidence Interval \\
\hline Poached & $49 \%$ & $34 \%-63 \%$ \\
Depredated & $9 \%$ & $1 \%-17 \%$ \\
Undisturbed & $42 \%$ & $28 \%-57 \%$ \\
\hline
\end{tabular}

